\title{
ADVERTISING TO ARCHITECTS: CREATING DESIRE AND ESTABLISHING CREDIBILITY IN THE CASE OF ALUMINIUM
}

\author{
PAUL HOGBEN \\ Faculty of the Built Environment \\ University of New South Wales \\ NSW 2052, Australia
}

PaulH@fbe.unsw.edu.au

\begin{abstract}
Media advertising, sponsorship deals and office visits are some of the main mechanisms through which manufacturers and suppliers attempt to place their materials and products before architects and find a way into professional consciousness. As scholarly interest in the promotional practices of manufacturers and their agents builds, there is a need to formulate and discuss analytical terms and tools for this research. The paper puts forward two terms through which the promotion of new materials and products to architects can be studied: desire and credibility. As a case study, it examines the introduction of aluminium as a building material in Australia in the mid-1930s and its subsequent promotion to become a major part of building construction in the 1950s.
\end{abstract}

Keywords: advertising, architects, building materials, building products, marketing, promotion, desire, credibility, aluminium.

\section{Introduction}

In the historical study of building materials, their manufacture and application in the production of architecture, there are a number of studies that consider the specific processes and devices through which materials and products have been promoted to architects. Patricia Cusack has examined the role played by institutional bodies and the journal, Concrete and Constructional Engineering, in promoting independent standards for the use of reinforced concrete amongst British architects in the early twentieth century. In her study of the modernization of existing buildings in the United States during the 1930s, Gabrielle Esperdy recognizes the importance of the marketing activity of material manufacturers to shifts in professional attitudes towards this type of work. In Exporting American Architecture 1870-2000, Jeffrey W. Cody describes the channels through which American materials, building technologies and construction methods have been marketed in different countries. These studies show that building material and product marketing is not a negligible influence on architectural practice. Indeed, over the twentieth century, building material and product marketing has attempted to live close to the world of architects and to permeate the day-to-day tasks of building design and documentation. There are the regular office visits by company representatives promoting the latest catalogues and trade literature making sure office libraries and records are up to date and new products are made known. There is the litany of glossy product magazines and brochures that are distributed 
and the sponsorship deals upon which many architectural exhibitions, conferences and other events depend. Then there is the ubiquitous flow of product advertising within architectural and building journals and magazines which is produced in the faith that advertising is seen and taken notice of by architect-readers.

In a previous paper I outlined several analytical and thematic considerations for the study of building product advertising (Hogben). Drawing from the work of Judith Williamson and others, the aim of that paper was to show how building product advertisements can be read in detail and unpacked in terms of semiotic analysis. This paper continues this research by proposing that studies can benefit from the examination of two concerns that come into play in the promotion of new materials and products to architects. These two concerns are those of creating desire and establishing credibility. In the well-known A-I-D-A copy formula of "get attention, hold interest, arouse desire, obtain action", desire is a linchpin of the advertising mechanism. What constitutes a desirable idea or image depends on the difference between a perceived lack and the promise of its fulfilment. The illusionary creation of this promise is where advertising makes its play. The question as to what constitutes this space for professional architects is an interesting one and one that promoters and advertisers have configured in various, and often simplistic, ways.

Apart from the imperative to create desire for a new material or product, promoters and advertisers also need to couple this with statements about a material or product's credibility. Credibility depends on technical reliance and also on professional, intellectual and theoretical associations and backings. Generally, advertising cannot contain detailed arguments but rather presents signifiers of integrity and trustworthiness: images, messages and endorsements that provide an aura of seriousness and believability. There have been several consistent strategies for establishing credibility, even in experimental times such as the ones examined here.

To provide a focus and test case for the study, the paper considers the introduction of aluminium as a building material to architects in Australia in the mid-1930s and the rapid takeup of this material in different product forms in the 1950s. The year 1884 saw the first recorded use of aluminium as a building material for the cap of the Washington Monument, yet it was only in the 1920s in the United States and to a lesser extent in Europe that architects started to really appreciate its applications to building construction (Kelley). Aluminium possessed the qualities of being light-weight, non-corrosive, durable, easy to extrude and strong in certain alloy combinations and promoters saw its potential as a substitute for traditional building materials such as copper, bronze, brick and terra-cotta, even structural steel. The introduction of aluminium as a modern building material to architects in Australia occurred under particular discursive circumstances in which desire was a very real factor in the manner of its reception and subsequent promotion.

\section{2 "The most modern of commercial metals"}

Aluminium as a building material was theoretically introduced to architects in Sydney through Norman Warren Waterhouse, an engineer, who had travelled to the United States in the early 1930s and upon his return became an expert on the material and wrote a number of articles for Architecture, the journal of the New South Wales Chapter of the R.A.I.A. In December 1935 he addressed a Chapter meeting and presented an outline of the history and uses of aluminium, "the most modern of commercial metals" (34). Waterhouse explained that aluminium was no longer a novelty for architects in the United States and Europe and was now an "established building material" (34). He described in detail the specification options for aluminium and its different alloys. After this, Waterhouse presented a number of examples where aluminium was seen en mass, including the Empire State Building $(5,704$ cast spandrels and internal decoration), the Field Building in Chicago (3,244 cast aluminium spandrels and 3,285 aluminium windows) and the Waldorf-Astoria Hotel in New York City $(26,000$ lbs. of cast spandrels as well as skylights and 3,100 aluminium chairs). The most spectacular example was the Rockefeller group of buildings which were under construction during his visit and which would employ a wide range of aluminium applications. Waterhouse reported,

The total weight of aluminium in the project is $3,000,000 \mathrm{lbs}$., and 700,000 sq. feet of surface area is aluminium, including 22,000 cast spandrels, approximately $1 / 6^{\text {th }}$ of the exterior surface of all buildings forming the group, being of aluminium. Many of the spandrels weigh 100 pounds each, and have a semi-lustrous appearance between the limestone pilasters forming the façades of the various units of the development. Due to the use of aluminium in this construction, the reduction in weight on the columns and foundations amounted to 3,000 tons (42). 
The images Waterhouse used to illustrate his lecture not only depicted buildings of a scale completely foreign to Australian cities but were also striking in their photographic style and intensity. One of these images showed an aerial view of the R.C.A. building of the Rockefeller Centre with a Pitcairn autogiro passing over the rising building in a show of twin modernity (Figure 1).

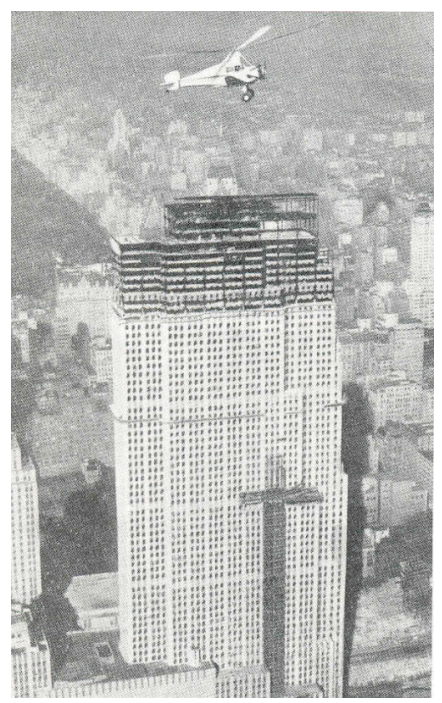

Figure 1: R.C.A. Building, Rockefeller Centre, New York City. From N. Warren Waterhouse, "Aluminium in Architecture," Architecture 25, 1(February 1936): 38

Many of those at the meeting were stunned at the promise of this material. The President of the Chapter, Arthur W. Anderson, thanked Waterhouse for his "most interesting lecture" and said, "[i]n this part of the world the structural uses, the size, the colour and the application of aluminium is all very new. It appears to have so many different forms, types, styles, etc., that its usefulness is not yet fully comprehended; it is indeed a truly wonderful material" ("Royal Australian Institute of Architects" 22). Colonel Hurst stated that aluminium would "open up a new vista altogether for us" and that "[i]ts uses are so varied that it will fill every want that we have known in the past" ("Royal Australian Institute of Architects" 22).

These enthusiasms for aluminium existed in a realm of desire: marvellous properties and images offering Sydney architects a view of an architectural present in other places and of a material that possessed almost inexplicable possibilities for a profession that was struggling with wasteful and restrictive construction by-laws (Ward 114). In the late 1930s terra-cotta, granite and sandstone remained the main facing materials for major commercial buildings. Wunderlich even had to explain what spandrels were in its advertising. Added to this, there was no aluminium smelter plant in Australia until 1955 and all raw supplies needed to be imported. As it happened, Waterhouse became the local representative for Aluminium Union Limited of Britain, the only aluminium advertiser in Architecture in the late 1930s. War curtailed the promotional momentum built by Waterhouse as the government placed restrictions on the use of building materials for non-military architectural work.

\section{Scientific Credibility as Promotional Image}

Pre-war enthusiasm and desire for aluminium amongst Sydney's architectural fraternity was mostly fostered by individuals like Waterhouse and images of otherness. This changed after the war with the emergence of the Australian Aluminium Company Pty. Ltd. (AAC) as the major local fabricator of aluminium products using imported feed. Established in Granville, Sydney, in 1936, the AAC's production was initially limited to military requirements, but once war-time restrictions were lifted it expanded operations and in 1948 began advertising its name and brand of aluminium alloys to the architectural profession. In July that year it initiated an advertising campaign that centred on the theme of "The $3^{\text {rd }}$ Metal Age." Published in Architecture from 1948 to 1950 , its advertisements promoted aluminium as a modern, universal material with exceptional versatility and advantages over other metals. Each advertisement contained an image or set of images that showed laboratory settings and testing equipment meant to represent the research laboratories of the AAC (Figure 2). The realism of these 
images was reinforced through the technical captions and a visual emphasis on the objectivity of scientific observation and measurement.

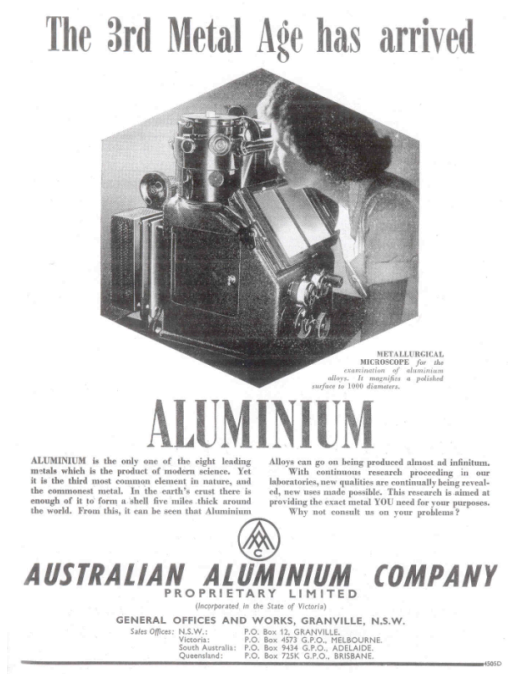

Figure 2: Advertisement from Architecture 37, 2(April 1949): xxiii

Inspiration for this campaign is evidently found in the juggernaut of scientific building research that had taken hold of architectural discourse in Australia by the mid-1940s. The Commonwealth Experimental Building Station was established in June 1945 and was modelled on the Building Research Station in England which already had a 25-year history of scientific research into building materials and methods. "Scientific building" and "strictly objective" reporting became the catch-cries of Institute Presidents, journal editors and outside advisers. Technical notes and publications on materials were issued from research organizations. According to Perth architectural educator, W. H. Robertson, the influx of new, scientifically formulated information would revolutionize professional approaches to materials and construction technology: "to arrive at a reliable judgment, we must adopt an attitude of scientific enquiry and approach. . . . To-day, methods of experiment and scientific enquiry can establish in months what the past could do only in centuries. Architectural conceptions, thus widened by the time dimension, are released from the restrictions imposed by empirical methods" (43).

To overcome the lack of empirical familiarity in Australia with architectural uses of aluminium, the strategy of the AAC campaign was to dramatize laboratory realism and tap into the prevailing discourse of science and professionalism and thereby create at the same time a sense of desirability and credibility for their product brand. Furthermore, whilst the advertisements projected an image of objectivity and controlled testing, they also appellated the viewer into a position of authority and centrality by stating that "This research is aimed at providing the exact metal YOU need for your purposes." A seductive mechanism was incorporated into the circuitry of this campaign that offered the viewer a feeling of ultimate control over need and usage, hence not compromising the idea of the viewer-architect as the design authority. To complete the loop, the AAC placed itself as the source for advising the viewer on the modern qualities and potentials of the material.

Promotional ploy masked as objective appeal was not new to building product advertising, but the themed nature of the AAC campaign with its particular usage of scientific language and visual references is important to the manner in which architectural credibility was being configured in the post-war promotional environment and to the AAC's strategy for creating a professional market for itself.

\section{$4 \quad$ Advertising the Curtain Wall}

Once Australia's aluminium smelter industry was in operation in 1955, competition between aluminium product manufacturers quickly grew. The AAC continued to advertise in the R.A.I.A.'s journal and was joined by Pain MFG. Pty. Ltd. (makers of Mello-Lite awnings and venetians), Selley's Chemical Manufacturing Co. Pty. Ltd. (aluminium glazing), Wunderlich Limited, Econo Steel Company and H. T. Worrall \& Sons Pty. Ltd. The market for architectural aluminium had 
expanded into residential design and whilst journal advertising reflected this, the major and most lucrative market was commercial office building construction and the embrace of the curtain wall as its primary architectural treatment. Curtain walling consisted of light-weight materials: glass modulated by aluminium frames. As curtain wall buildings started to appear in Australian cities, so too did the sale offices of aluminium companies. The AAC had established offices in all major mainland cities, and other companies followed, and by 1957 architects faced a fiercely competitive promotional and sales environment. It had become an aluminium age. The emphasis of advertising campaigns at the time had shifted distinctly away from the laboratory realism of the 1940 s to a display of scale and productive capacity. Advertisements centred on images of buildings held up as trophies for particular producers with strong perspectives signifying not only the visual sleekness of curtain wall design but also corporate uniformity and strength of direction.

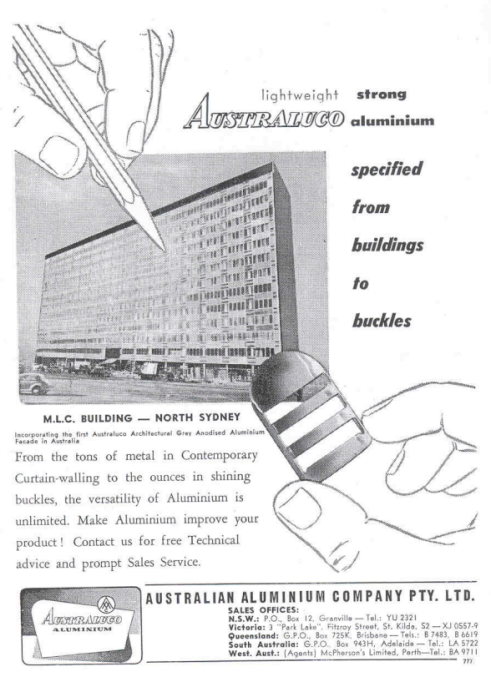

Figure 3: Advertisement from Architecture in Australia 46, 3(July-September 1957): 34

This advertising used certain "hooks" to attract attention, foster desire and establish credibility. Firstly, it featured buildings on the drawing board, models of buildings and photographs of completed buildings, all of which were said to be connected to a particular aluminium product or supplier. Whether on the drawing board or as a real edifice, these buildings were shown in a very productive light and advertisements implied that the use of the advertised product resulted in success of production at a large scale. With the amount of new office buildings being commissioned and constructed in the mid-to-late 1950s this message was designed to carry persuasive power. It was a common strategy and used consistently which suggests it was considered effective. Secondly, advertisements featuring images of buildings were published in conjunction with review articles and illustrations of the same buildings. This was the case with Figure 3 and the publication of the M.L.C. Building in North Sydney by Bates, Smart \& McCutcheon in the July-September 1957 issue of Architecture in Australia. Another example is the publication of the Qantas Building in Sydney and the advertising that accompanied it. The profiling and review of these buildings in the Institute's journal bestowed a professional credibility on the building, its design and material construction, which the advertisers could then exploit for their own purposes. Thirdly, several of the advertisements at this time made reference to American buildings and claimed their product makers had knowledge of or were using American testing procedures (Figure 4). This reference to American practice was a powerful hook considering the interest in America and American architecture that pervaded the Australian profession in the 1950s. Pietro Belluschi, Dean of M.I.T., was a keynote speaker at the 1956 R.A.I.A. convention and during his address showed a large range of slides depicting vast building projects recently constructed in the United States. Fourthly, advertising continued to use the themes of realism and objectivity but unlike the advertisements of the 1940s this time the viewer was appellated with promises of commercial success and achievement. The scientific neutrality projected by the earlier campaigns had changed to an open display of corporate building ambition. 


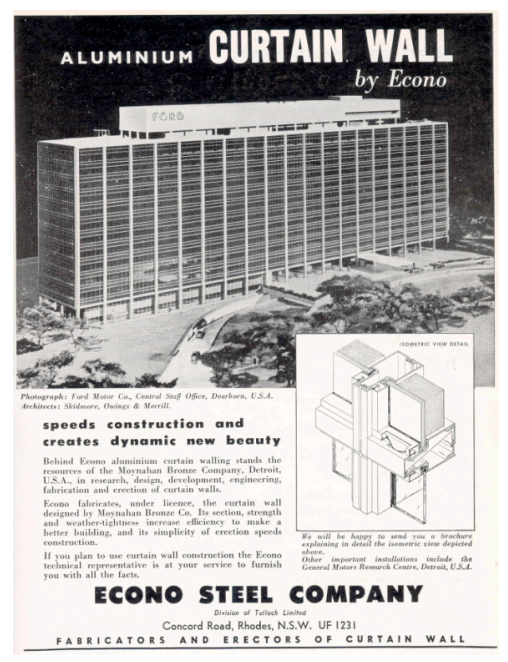

Figure 4: Advertisement from Architecture in Australia 46, 3(July-September 1957): 23

\section{Conclusion}

This paper has shown that advertisers have attempted to draw attention to a given material product (in this case aluminium) through the use of hooks that were intended to create desire and at the same time present a credible impression. Campaigns have been built on tapping into desire for the modern, the flexible, the scientifically approved and the commercially productive. These campaigns have appeared when there has been a growth in enterprise and a drive to expand and develop markets and the focus here has been on how aluminium promoters and companies have addressed and advertised their products to architects in Australia.

Such a study can contribute to a larger history of the promotion of modern materials and products to the architectural profession in Australia. Conceived both in international and national terms (as many products have been part of an import trade), such a history (or histories) would show that the introduction of new materials and products and their incorporation into the lexicon of architectural design is a nexus of industrial, commercial, promotional and professional interests. There are a number of documented histories of Australian architectural practices and firms such as Bates Smart (who were major users and beneficiaries of the aluminium industry in the 1950s) and the argument here is that there now needs to be an expansion of focus to consider the industrial and promotional complexes in which their material preferences were formed. This case study is presented as an explorative foray into this field by foregrounding terms and themes through which we can begin to locate lines of connection.

\section{References}

Cody, Jeffrey W. Exporting American Architecture 1870-2000. London and New York: Routledge, 2003.

Cusack, Patricia. "Architects and the Reinforced Concrete Specialist in Britain 1905-08." Architectural History 29(1986): 183-196.

Esperdy, Gabrielle. "The Odd-Job Alleyway of Building: Modernization, Marketing, and Architectural Practice in the 1930s." Journal of Architectural Education 58, 4(2005): 25-40.

Hogben, Paul. "The Look of Expertise: Towards a History of Building Product Advertising." Transition 61/62(2000): 30-38, 173.

Kelley, Stephen J. "Aluminum." In Twentieth-Century Building Materials: History and Conservation, edited by Thomas C. Jester, 46-57. New York: McGraw-Hill, 1995.

Robertson, W. H. "Some Suggestions for the Advancement of Architecture." Architecture 36, 2(April 1948): 43-46.

"The Royal Australian Institute of Architects: New South Wales Chapter: Minutes of Ordinary General Meeting, December 3, 1935.” Architecture 25, 1(January 1936): 22.

Ward, Dudley. "Modern Methods of Construction." Architecture 24, 6(June 1935): 114-116.

Waterhouse, N. Warren. "Aluminium in Architecture." Architecture 25, 1(February 1936): 34-43. 